\title{
Treatment of staphylococcal septic arthritis in rabbits by systemic antibiotics and intra-articular corticosteroids
}

\author{
A J Wysenbeek, J Volchek, M Amit, D Robinson, I Boldur, Z Nevo
}

\begin{abstract}
Objective-To assess the effect of intraarticular corticosteroids added to systemic antibiotics in experimental septic arthritis.

Methods-Rabbits were injected intraarticularely by Staphylococcus epidermidis. Rabbits received no additional treatment and served as control (group 1), were treated with systemic antibiotics (group 2), or treated with systemic antibiotics and intra-articular corticosteroids (group 3). After 15 days animals were killed and joint histopathologicalhistochemical parameters were assessed. Results-All rabbits survived the experiment. The treated groups (2-3) had lower histological-histochemical scores in comparison with the untreated group (1). Group 3 had significantly lower scores in joint sections in comparison with group 2: (mean (SD) 6.5 (1.4) $v 4.0$ (1.0), $\mathrm{p}=0.001$ and $7.4(2.6) v 4.2(2.2), \mathrm{p}=0.01)$, because of lower damage expressed in clustering of chondrocytes, pannus formation, proteoglycan depletion, and synovitis.

Conclusion-Addition of local corticosteroids to systemic antibiotics in septic arthritis seems to be harmless, and improves joint histological-histochemical parameters in this experimental setting. (Ann Rheum Dis 1998;57:687-690)
\end{abstract}

Department of Medicine B, Assaf Harofeh Medical Centre, Zerifin, Israel A J Wysenbeek J Volchek M Amit

Department of Clinical Biochemistry, Sackler

School of Medicine, Tel

Aviv University, Israel

Z Nevo

D Robinson

Department of Microbiology, Assaf Harofeh Medical Centre, Zerifin, Israel I Boldur

Correspondence to: Professor A J Wysenbeek, Department of Internal Medicine B, Assaf Harofeh Medical Centre, Zerifin 70300, Israel.

Accepted for publication 6 August 1998 to improve prognosis in acute bacterial meningitis. ${ }^{89}$

In a preliminary study of experimental septic arthritis, we showed that adding intra-articular corticosteroids to systemic antibiotic the corticosteroid treatment did not induce damage. ${ }^{10}$ The present study was performed on a larger scale, to compare histopathologicalhistochemical parameters in staphylococcal arthritis not treated, treated by antibiotics, or treated with systemic antibiotics and local corticosteroids.

\section{Methods}

ANIMALS

Thirty, eight week old, New Zealand rabbits, weighing 2 to $3 \mathrm{~kg}$, were used in our experiments. The rabbits lived in laboratory cages with an ad libitum supply of food and water, and under standard temperature and light conditions.

BACTERIAL STRAIN AND CULTURE CONDITIONS The Staphylococcus epidermidis, used in the experiments described below, was originally isolated from the blood of a patient with bacteraemia. The bacterial strain was cefonicid sensitive.

EXPERIMENTAL PROTOCOL

All of the eight week old rabbits were housed in individual cages. Their left knees were inoculated with $0.5 \mathrm{ml}$ of a Staphylococcus epidermidis suspension $\left(2 \times 10^{4}\right.$ cells $\left./ \mathrm{ml}\right)$ in physiological saline-phosphate buffered saline (PBS) on day 0.

The animals were divided into three groups: group $1(n=10)$ control group: infected with Staphylococcus epidermidis only and were not further treated; group $2(n=10)$ : after infection with Staphylococcus epidermidis, treated with daily intramuscular cefonicid injections, 50 $\mathrm{mg} / \mathrm{kg}$. The treatment began 24 hours after infection and continued for 14 days, until the termination of the experiment; group 3 $(n=10)$ : after infection with Staphylococcus epidermidis, cefonicid was administered as in group 2. Methylprednisolone acetate, $5 \mathrm{mg}$, was injected intra-articulary into the infected left knee 48 hours after infection and 24 hours after the start of antimicrobial treatment.

On the 15th day after the beginning of the experiment all of the rabbits were killed with an overdose of sodium thiopentothal. Both posterior knees were removed and subjected to fixation with formalin- $0.5 \%$ CPC (cetylpyridinium chloride) for two days, followed by regular 
Table 1 Histopathological and histochemical scoring

\begin{tabular}{|c|c|c|}
\hline \multicolumn{2}{|c|}{ A Histopathological-histochemical scoring parameters: } & \multirow[t]{2}{*}{ Score (12) } \\
\hline 1 & Cellularity & \\
\hline & Normal cellularity & 0 \\
\hline & $<10 \%$ of acellular cartilage & 1 \\
\hline & $10-50 \%$ of acellular cartilage & 2 \\
\hline & $>50 \%$ of acellular cartilage & 3 \\
\hline \multirow[t]{5}{*}{2} & Loss of matrix (erosion of the articular ce & \\
\hline & No loss & 0 \\
\hline & $<10 \%$ of eroded regions & 1 \\
\hline & $10-25 \%$ of eroded regions & 2 \\
\hline & $>25 \%$ of eroded regions & 3 \\
\hline \multirow[t]{5}{*}{3} & Clustering of chondrocytes (propagating & \\
\hline & No clustering & 0 \\
\hline & $<10 \%$ of chondrocytes in clusters & 1 \\
\hline & $10-25 \%$ of chondrocytes in clusters & 2 \\
\hline & $>25 \%$ of chondrocytes in clusters & 3 \\
\hline \multirow[t]{5}{*}{4} & Adhesions (pannus) & \\
\hline & No adhesions & 0 \\
\hline & Covering only the margins of cartilage & 1 \\
\hline & Covering $<50 \%$ of articular surface & 2 \\
\hline & Covering $>50 \%$ of articular surface & 3 \\
\hline \multirow[t]{5}{*}{$5^{\star}$} & Orthochromasia with Alcian blue & \\
\hline & Normal & 0 \\
\hline & Slight and patchy loss of staining $(\times 1-2)$ & 1 \\
\hline & Moderate loss $(\times 2-3)$ & 2 \\
\hline & Severe loss $(\times 4-5)$ & 3 \\
\hline \multirow[t]{5}{*}{6} & Significance of synovitis reflected by infla & nbrane \\
\hline & Normal synovia & 0 \\
\hline & Mild cellular infiltration of synovia & 1 \\
\hline & Moderate cellular infiltration of synovia & 2 \\
\hline & Severe cellular infiltration of synovia & 3 \\
\hline \multicolumn{3}{|c|}{ B Additional histopathological cartilage scoring: } \\
\hline 1 & \multicolumn{2}{|c|}{ Vascular elements crossing of cartilage-subchondral bone tidemark } \\
\hline 2 & \multicolumn{2}{|c|}{ Height of articular cartilage zone } \\
\hline 3 & \multicolumn{2}{|l|}{ Enchondral bone marrow cavities } \\
\hline
\end{tabular}

fixation with formalin-saline for seven days. The samples underwent decalcification with EDTA, for the next six weeks. Subsequently, the samples were cut into four parts and embedded in paraffin wax forming blocks in which the tissue samples were positioned to allow sectioning in different orientations. Five to eight $\mu \mathrm{m}$ thick slices were cut parallel and perpendicular to the cartilage surface by a standard microtome. The samples were stained by routine techniques, with haematoxylin and eosin, Masson's-trichrome and Alcian blue (at $\mathrm{pH} 1.0$ and 2.5) staining, specifically for mucopolysaccharides. ${ }^{11}$

HISTOPATHOLOGICAL EXAMINATION

The various slides were coded, mixed, and assessed by a blinded observer (JV). The joints were studied with regard to histopathologicalhistochemical scoring parameters. ${ }^{12}$ They were also assessed for vascular elements crossing the cartilage subchondral bone tidemark, ${ }^{13}$ height of cartilage zone, ectopic-enchondral bone marrow cavities, and degree of synovial infiltration (table 1).

\section{IMAGE ANALYSIS}

The various parameters were scored with the assistance of an image analysis system (Java, Jandell Corp, Corte Madera, California). In brief, an image was captured using an image grabber and a video camera connected to the microscope. The slides were examined in one session and lighting conditions were kept constant. The session did not last more than four hours, as heating of the video camera tends to change the results of densitometric measurements.
The morphological parameters were measured. Cellularity of cartilage was determined as a function of nuclei density. Nuclei density was defined as number of nuclei per square area of cartilage matrix. A density that was three standard deviations less than the average of normal cartilage was defined as acellular cartilage. The percentage of eroded joint surface was calculated as length of eroded surface divided by total joint surface length in a photomicrograph. Clustering of chondrocytes was determined as number of clones divided by total number of chondrocytes. Pannus formation was measured as length of joint surface covered by pannus divided by total length of joint surface in a photomicrograph.

Orthochromasia was measured by comparing the optical density in the grabbed image of the cartilage as averaged over non-cellular areas of the matrix with controls. Two controls were examined - that is, normal cartilage (containing a large amount of proteoglycans and demonstrating a strong degree of orthochromasia) and normal bone (containing virtually no proteoglycans, and demonstrating minimal orthochromasia). Values were measured on a 256 degree scale, where 0 represents maximal optical density (absolute black) and 255 represents minimal optical density (absolute white).

The parameters of vascular crossings of tidemark and enchondral bone marrow cavities were qualitatively assessed. Average cartilage height was measured by the image analyser.

\section{STATISTICS}

Data were analysed on the SPSS/PC statistical system. Because of the ordinal variables and non-parametric distribution of data, groups were compared by the Mann-Whitney nonparametric test. Values of 0.05 or less were considered as statistically significant.

\section{Results}

All animals survived the 15 day experiment.

After termination of the experiment and joint capsule opening, pus was observed in seven joints of the bacteria inoculated rabbits without any further treatment. No pus was observed in antibiotic treated rabbits, but synovia was hyperaemic and mildly swollen. Rabbits treated with antibiotics and corticosteroids disclosed no synovial swelling but mild hyperaemia.

Figure 1 shows an example of normal proteoglycans in a control knee (A), and severe proteoglycan depletion in a septic knee of group 1 (B). Figure 2 shows a septic knee of group 2, with pannus formation and an erosion.

Table 2 shows the results of the scoring, which summarises scorings of horizontal and vertical femoral sections.

As shown, total scores of the antibiotic treated animal groups were lower in comparison with the untreated group (mean (SD) 8.2 (1.9) $v 6.5$ (1.4), $\mathrm{p}=0.02$ and 8.8 (2.5) $v 7.4$ (2.6) $\mathrm{p}=\mathrm{NS}$ ). This lower score with antibiotic treatment is because of the lower damage expressed in pannus formation, proteoglycan depletion, and synovitis. 

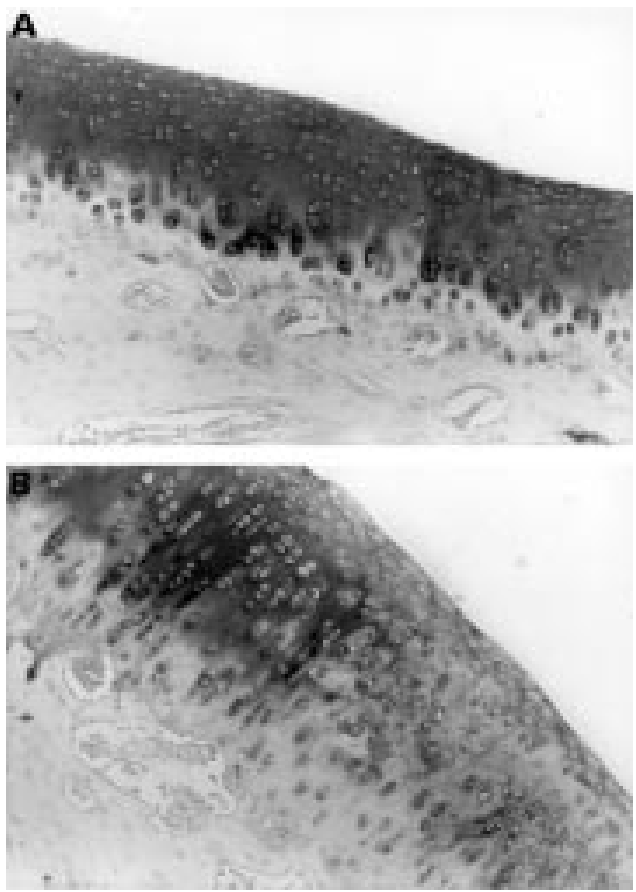

Figure 1 Normal proteoglycans from a control knee $(A)$, and severe proteoglycan depletion, septic knee, group 1 (B). Stained with Alcian blue $\times 100$.

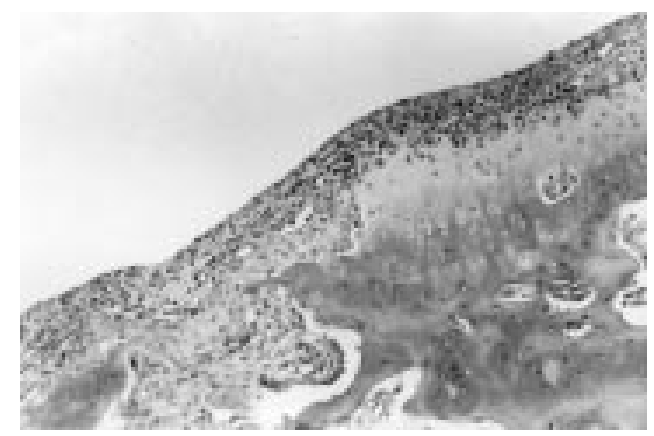

Figure 2 Pannus covering cartilage and erosion, group 2. Stained with Masson's trichrom $\times 100$.

When studying the corticosteroid influence, it can be seen that group 3 (antibiotic + corticosteroid) has a significantly lower total score in comparison with group 2 (antibiotic) (mean

Table 2 Histopathological and histochemical scorings of horizontal (A) and vertical (B) sections of femur. Grading according to table 1

\begin{tabular}{lllll}
\hline Group & & 1 & 2 & 3 \\
\hline \% Acellular cartilage & $\mathrm{A}$ & $2.1(0.3)$ & $2.2(0.4)$ & $2.0(0.0)$ \\
& $\mathrm{B}$ & $2.0(0)$ & $2.0(0)$ & $1.8(1.8)$ \\
Loss of matrix (erosion) & $\mathrm{A}$ & 0 & 0 & 0 \\
Clustering & $\mathrm{B}$ & $0.7(0.8)$ & $0.8(0.9)$ & $0.4(0.5)$ \\
& $\mathrm{A}$ & $1.5(0.7)$ & $2.1(0.8)$ & $1.4(0.8)$ \\
Pannus & $\mathrm{B}$ & $1.2(0.6)$ & $1.3(0.9)$ & $0.9(0.6)$ \\
& $\mathrm{A}$ & $0.6(0.7)$ & $0.1(0.3)$ & $0.1(0.3)$ \\
Orthochromasia (proteoglycan & $\mathrm{B}$ & $1.1(1.0)$ & $0.8(0.8)$ & $0.2(0.4)$ \\
depletion) & $\mathrm{A}$ & $1.7(0.9)$ & $1.0(0.8)$ & $0.2(0.4)^{\star}$ \\
Severity of synovitis & $\mathrm{B}$ & $1.9(0.7)$ & $1.3(0.8)$ & $0.2(0.4)^{\star}$ \\
& $\mathrm{A}$ & $2.3(0.8)$ & $1.1(0.9)$ & $0.3(0.7)^{\star}$ \\
Vascular elements crossing the tidemark & $\mathrm{B}$ & $2.2(0.9)$ & $1.3(1.1)$ & $0.6(0.9)$ \\
Enchondral bone marrow cavities & $\mathrm{A}$ & $0.5(0.5)$ & $0.6(0.5)$ & $0.5(0.5)$ \\
& $\mathrm{B}$ & $0.4(0.5)$ & $0.5(0.5)$ & $0.1(0.3)$ \\
& $\mathrm{A}$ & $0.4(0.5)$ & $0.4(0.5)$ & $0.3(0.5)$ \\
Height of cartilage & $\mathrm{B}$ & $0.3(0.4)$ & $0.5(0.5)$ & $0.2(0.4)$ \\
Total score & & & & \\
& $\mathrm{A}$ & $97.6(2.9)$ & $89.5(5.9)$ & $90.8(9.1)$ \\
& $\mathrm{B}$ & $97.3(5.7)$ & $91.0(13.1)$ & $100(0)$ \\
& $\mathrm{A}$ & $8.2(1.9)$ & $6.5(1.4)$ & $4.0(1.0)^{\star}$ \\
& $\mathrm{B}$ & $8.8(2.5)$ & $7.4(2.6)$ & $4.2(2.2)^{\star}$ \\
\hline
\end{tabular}

${ }^{\star} \mathrm{p}<0.05$ between groups $2-3$. Data shown as mean (SD).
(SD) 6.5 (1.4) v 4.0 (1.0), $\mathrm{p}=0.001$ and 7.4 (2.6) $v 4.2(2.2), \mathrm{p}=0.01)$. This lower score in the corticosteroid group is because of the lower damage expressed in clustering of chondrocytes, pannus formation, proteoglycan depletion, and synovitis.

\section{Discussion}

The aim of this study is to diminish articular damage in bacterial arthritis, which occurs regardless of the present common appropriate treatment. The theoretical basis for the combined antibiotic immunosuppressive approach is that local articular damage may be secondary to activation of the host immune system. In previous studies antioxidants such as superoxide dismutase were used to neutralise release of free oxygen radicals. ${ }^{14}$ However, this treatment was unsuccessful, as was treatment with aspirin and antibiotic in experimental septic arthritis. ${ }^{15}$ On the other hand, treating animals with nonsteroidal anti-inflammatory drugs before and during induction of arthritis, which was then treated by antibiotics, decreased joint damage. ${ }^{16}$

In our previous study we showed that combined antibiotic-corticosteroid treatment seems to have no adverse effects. ${ }^{10}$ We suggested that contraindications to local corticosteroids in septic arthritis, as quoted in pertinent textbooks, ${ }^{18}{ }^{18}$ are unjustified, as long as systemic antibiotics are combined with the corticosteroids.

Staphylococcus aureus is the most prevalent bacteria in septic arthritis and in animal models. We used Staphylococcus epidermidis, which is also involved in septic arthritis, ${ }^{2}$ because of its lower virulence. We postulated that this will give us a better observation of corticosteroid effect. No joint aspiration and drainage was performed, although this can improve therapeutic response, because of the rabbits sensitivity to repeated trauma.

In this study we showed that the combined treatment of antibiotics and corticosteroids may have advantages over antibiotics alone. Animals with combined treatment had statistically significantly less proteoglycan depletion and synovitis. They also had less erosions, clustering of chondrocytes, pannus formation, and enchondral bone marrow cavities. This led to a significantly lower histopathologicalhistochemical score in both section planes.

Stricker reported concomitantly to our study the effect of bethametasone on experimental septic arthritis. ${ }^{19}$ His results of reduced proteoglycan loss are in accordance with our findings. He showed that this chondroprotection was more pronounced in the group treated by systemic corticosteroids than in the group treated with local corticosteroids. However, in that study a lower dose of local corticosteroids was used, about $50 \%$ of the corticosteroid potency in our experiment. These dose differences, as well as long duration of action of methylprednisolone acetate, used in our study, might explain the more pronounced effect we observed with intra-articular corticosteroids.

In another recent study of murine septic arthritis, Sakiniene added systemic corticoster- 
oids to antibiotics. ${ }^{20} \mathrm{He}$ showed that the corticosteroid treated group had less mortality, and less synovial infiltration in accordance with our observation. He showed that the course of arthritis was improved because of down regulation of $\mathrm{T}$ and $\mathrm{B}$ lymphocytes and macrophage function.

Thus, our study, as well as the two other reported studies, show a favourable effect of corticosteroids in septic arthritis. These results should be interpretated with caution, because there are no data showing the long term effect on permanent damage by this therapeutic approach. However, adding corticosteroid to antibiotics seems not only to be harmless, but might be beneficial.

1 Goldenberg DL. Bacterial arthritis. In: Kelley WN, Harris ED, Ruddy S, Sledge CB, eds. Textbook of rheumatology. 5th ed. Philadelphia: Saunders, 1997:1435-49.

2 Ike RW. Bacterial arthritis. In: Koopman WJ, ed. Arthritis and allied conditions. 13th ed. Baltimore: Williams and Wilkins, 1997:2267-95.

3 Howard JB, Highgenboten CL, Nelson JD. Residual effects of septic arthritis in infancy and childhood. JAMA 1976;236:932-5.

4 Riegels-Nielsen P, Frimodt-Moller N, Sorensen M, Jensen S. Antibiotic treatment insufficient for established septic arthritis. Acta Orthop Scand 1989;60:113-15.

5 Smith R L, Schurman D J, Kajiyama G, Mell M, Gilkerson E. The effect of antibiotics on the destruction of cartilage in experimental infectious arthritis. J Bone Joint Surgery 1987;69A:1063-8.

6 Saez-Llorens X, Mustafa M M, Ramilo O, Fink C, Beulter B, Nelson J D. Tumor necrosis factor $\alpha$ and interleukin $1 \beta$ in synovial fluid of infants and children with suppurative arthritis. Am J Dis Child 1990;144:353-6.

7 Williams RJ, Smith RL, Schurman DJ. Septic arthritis. Willams RJ, Smith RL, Schurman
8 Tuomanen E. Breaching the blood-brain barrier. Sci Am 1993;2:80-4.

9 Lebel MH, Freij BJ, Syrogiannopoulos GA, Chrane DF, Hoyt MJ, Stewart SM, et al. Dexamethasone therapy for bacterial meningitis. N Engl J Med 1988;319:964-71.

10 Wysenbeek AJ, Leitman M, Amit M, Lushkov G, Robinson D, Boldur I, et al. Experimental septic arthritis in rabbits treated by a combination of antibiotic and steroid drugs. Clin Exp Rheum 1996;14:507-12.

11 Pearse AG. Histochemistry theoretical and applied. 3rd ed. Boston: Little, Brown, 1968:1:1-758, 1972:2:761-1518.

12 Salter RB, Bell RS, Keeley FW. The protective effect of continuous passive motion on living articular cartilage in acute septic arthritis. Clin Orthop Related Res 1981;159:223-47.

13 Mankin HJ, Dorfman H, Lippiello L, Zarins A. Biochemical and metabolic abnormalities in articular cartilage from osteo-arthritic human hips. J Bone Joint Surg 1971;53A: 523-37.

14 Linhart WE, Steinwender G, Weybora W, Zadravec S, Esterbauer $H$. Influence of superoxide dismutase on staphylococcal arthritis- A histological and biochemical investigation using an experimental animal model. Agents Actions 1990;29:259-65.

15 Boyer J, Daniel D, Akeson WH, Amiel D, Ryder M. Effect of salicylate therapy on cartilage destruction in experimental pyarthrosis. Clin Orthop 1977;126:302-4.

16 Smith RL, Kajiyama G, Schurman DJ. Staphylococcal septic arthritis: antibiotic and nonsteroidal anti-inflammatory drug treatment in a rabbit model. J Orthop Res 1997; 15:919-26.

17 Owen DC. Aspiration and injection of joints and soft tissues. In: Kelley W N, Harris ED, Ruddy S, Sledge CB, eds. Textbook of rheumatology. 5th ed. Philadelphia: Saunders, 1997:591-608.

18 Gatter RA. Arthrocentesis technique and intrasynovial therapy. In: Koopman WJ, ed. Arthritis and allied conditions. 13th ed. Baltimore: Williams and Wilkins, 1997:751-60.

19 Stricker SJ, Lozman PR, Makowski AL, Gunja-Smith Z. Chondroprotective effect of betamethasone in lapine pyogenic arthritis. J Pediatr Orthop 1996;16:231-6.

20 Sakiniene E, Bremell T, Tarkowski A. Addition of corticosteroids to antibiotic treatment ameliorates the course of experimental staphylococcus arthritis. Arthritis Rheum 1996;39:1596-605. 